\title{
Hippocampal Synaptogenesis in Cell Culture: Developmental Time Course of Synapse Formation, Calcium Influx, and Synaptic Protein Distribution
}

\author{
Trent A. Basarsky, Vladimir Parpura, and Philip G. Haydon \\ Signal Transduction Training Group and Department of Zoology and Genetics, lowa State University, Ames, lowa \\ 50011-3223
}

The formation of chemical synapses between hippocampal neurons in primary cell culture was studied using electrophysiology, calcium imaging, and immunocytochemical approaches. Inhibitory and excitatory synapses formed within $12 \mathrm{~d}$ in cell culture (DIC) that were sensitive to the $\mathrm{N}$-type calcium channel blocker $\omega$-conotoxin GVIA ( $\omega$-CgTx). At 4 DIC, immature connections were present in which spontaneous, but rarely evoked, synaptic currents were detected. At both 4 and 12 DIC, the synaptic proteins rab3a, synapsin I, and synaptotagmin were present in hippocampal neurons, but the subcellular distribution changed from one in which immunoreactivity was initially distributed within soma and neurites to a punctate varicose appearance. Correlated with the transformation from immature to mature synaptic states was the onset of $\omega$-CgTx-sensitive calcium influx. Taken together, these data suggest that the expression of functional $\omega$-CgTx-sensitive calcium influx is temporally coincident with synapse formation, and that during the maturation of the synapse there is a redistribution of synaptic proteins.

[Key words: synaptic proteins, synaptotagmin, synapsin, rab3a, synaptogenesis, calcium channel, conotoxin, $\omega-C g T x]$

Much of our knowledge about synaptogenesis has been gained from studies of neuromuscular development where agrin and aria, synthesized in motoneurons, regulate the expression and aggregation of postsynaptic ACh receptors (Falls et al., 1990; McMahan, 1990). For the development of fast synaptic transmission, it is also necessary that presynaptic macromolecules are synthesized, transported to the presynaptic terminal, and arranged with the appropriate mutual spatial relation. For example, it is necessary for the calcium channel to become localized in close proximity to the secretory vesicle to supply calcium in a sufficiently high concentration to stimulate secretion (Simon and Llinas, 1985; Zucker and Fogelson, 1986). It is also unclear whether different calcium channels are subject to the same regulation during synaptogenesis. For example, are L-type channels that do not stimulate transmitter release subject to similar reg-

\footnotetext{
Reccived Nov. 8, 1993; revised Mar. 4, 1994; accepted Apr. 13, 1994.

T.A.B. and V.P. contributed equally. We thank Kerry J. Morris and Robert Doyle for technical assistance, Drs. R. Jahn and A. Czernik for providing antibodies, and Dr. S. Shen for helpful discussion. This work was supported by the Epilepsy Foundation of America, NIH Grants NS26650 and NS24233, the Alfred P. Sloan foundation, and a Medical Research Council of Canada studentship (T.A.B.).

Correspondence should be addressed to P. G. Haydon, Signal Transduction Training Group and Department of Zoology and Genetics, 339 Science II, Iowa State University, Ames, IA 50011-3223.

Copyright (C) 1994 Society for Neuroscience $0270-6474 / 94 / 146402-10 \$ 05.00 / 0$
}

ulation as $\mathrm{N}$-type channels that do supply calcium to stimulate synaptic transmission (Takahashi and Momiyama, 1993)? Little information is available concerning the regulation of these presynaptic developmental events.

Studies of nerve-muscle synapse formation have shown that the synaptic target supplies retrograde signals that control the appropriate development of presynaptic machinery. Muscle cells manipulated into contact with growth cones of neurons derived from the Xenopus neural tube cause a local increase in resting calcium level (Dai and Peng, 1993), a rapid induction of secretion (Xie and Poo, 1986), and a local reorganization of the growth cone such that the quantal content of evoked synaptic transmission is augmented (Sun and Poo, 1987). In Helisoma, muscle fibers activate presynaptic protein kinase A, which causes an elevation of the resting calcium level of neuronal growth cones, and an enhancement of the presynaptic calcium influx during action potentials (Funte and Haydon, 1993; Zoran et al., 1993). After many hours of contact, the calcium sensitivity of the secretory apparatus is then increased (Zoran et al., 1991). These regulatory events lead to the effective coupling of presynaptic action potentials to secretion.

In contrast to studies of neuromuscular synapse formation, there is a paucity of studies of the regulation of synaptogenesis between central neurons. Central neurons can contain many types of calcium channels, yet only a restricted subset stimulates transmitter release (Takahashi and Momiyama, 1993). A priori, one would expect a differential regulation of these different subsets of calcium channels during synaptogenesis. Furthermore, it is unclear when specific calcium channels develop in relation to the onset of synapse formation, when and where synaptic associated proteins are expressed and when excitation becomes coupled to secretion. Using dissociated hippocampal cell cultures, the goal of this study is to elucidate the temporal relation between the appearance of functional synaptic transmission, Land $\mathrm{N}$-type calcium channels, and synaptic protein distribution. This study demonstrates that while many components of the presynaptic neuron are expressed early in cell culture the development of $\omega$-CgTx-sensitive $\mathrm{N}$-type, but not nifedipine-sensitive L-type, calcium influx is temporally correlated with the delayed detection of evoked synaptic transmission.

Some of these data have appeared in preliminary form (Basarsky et al., 1992).

\section{Materials and Methods}

Cell culture. Hippocampi were dissected from 1-4-d-old Sprague-Dawley rats. Tissue was incubated for $1 \mathrm{hr}$ at $37^{\circ} \mathrm{C}$ in $\mathrm{Ca}^{2+} / \mathrm{Mg}^{2+}$-free Earle's balanced salt solution (EBSS; pH 7.35; GIBCO) containing papain (20 
$\mathrm{U} / \mathrm{ml}$; Sigma), HEPES (10 mM), L-cysteine $(0.2 \mathrm{mg} / \mathrm{ml})$, glucose $(20$ $\mathrm{mm})$, penicillin $(100 \mathrm{U} / \mathrm{ml})$, and streptomycin $(100 \mu \mathrm{g} / \mathrm{ml})$. Tissue was washed once with fresh EBSS and then placed in EBSS (pH 7.35) containing HEPES (10 mM) and trypsin inhibitor $(10 \mathrm{mg} / \mathrm{ml}$, type II-O; Sigma) for $5 \mathrm{~min}$. After being rinsed, hippocampi were mechanically dispersed by triturating through a fire-polished glass pipette. Cells were plated into poly-L-lysine ( $1 \mathrm{mg} / \mathrm{ml}$, MW 100,000; Sigma)-coated glassbottomed dishes. Cultures were maintained at $37^{\circ} \mathrm{C}$ in a humidified $5 \%$ $\mathrm{CO}_{2}, 95 \%$ air atmosphere. Culture medium consisted of Eagle's minimum essential medium (Earle's salts, GIBCO) supplemented with 10\% heat-inactivated fetal bovine serum (FBS; Sigma) and containing $40 \mathrm{~mm}$ glucose, $2 \mathrm{~mm}$ L-glutamine, $1 \mathrm{~mm}$ pyruvate, $14 \mathrm{~mm} \mathrm{NaHCO}_{3}, 100 \mathrm{U} / \mathrm{ml}$ penicillin, and $100 \mu \mathrm{g} / \mathrm{ml}$ streptomycin $(\mathrm{pH} 7.35$ ). The dissociation procedure was modified from previously described procedures (Leifer et al., 1984; Huettner and Baughman, 1986; Mattson and Kater, 1989). To suppress proliferation of non-neuronal cells, arabinosylcytosine (ARAC; $5 \mu \mathrm{M}$ ) was added after 2-3 d in culture. Cultures were fed once a week by exchanging $30 \%$ of the medium with fresh medium.

Electrophysiology. Conventional dual whole-cell recording techniques (Hamill et al., 1981) were employed to stimulate and record synaptic currents from cultured hippocampal neurons that had been grown in cell culture for $1-21 \mathrm{~d}$. All experiments were performed at room temperature $\left(22-24^{\circ} \mathrm{C}\right.$ ). Normal external saline contained (in $\mathrm{mM}$ ) $\mathrm{NaCl}$, 140; HEPES, 10; KCl, 5; $\mathrm{CaCl}_{2}, 2 ; \mathrm{MgCl}_{2}, 2 ; \mathrm{pH} 7.35$ with $\mathrm{NaOH}$. Pipette solutions contained (in mM) K-gluconate, 140; EGTA, 10; $\mathrm{Mg}$ ATP, 4; GTP, 0.1; HEPES, 10; pH 7.35 with $\mathrm{KOH}$. The osmolarity of the external saline was adjusted with sucrose to be $10 \mathrm{mOsm}$ higher than the internal pipette solution. Pipettes fabricated from $1.5 \mathrm{~mm}$ o.d. borosilicate glass had D.C. resistances of 30-7 M 2 . Postsynaptic cells were voltage clamped at a range of -80 to $-30 \mathrm{mV}$ to test for the presence of excitatory and inhibitory synaptic transmission. Presynaptic cells were held in current clamp at $-60 \mathrm{mV}$. The presence of spontaneous synaptic events was assayed at holding potentials of -70 and $-40 \mathrm{mV}$ in the first $7 \mathrm{~min}$ after whole-cell access. Evoked connections between neuronal pairs was measured by current injection to induce action potentials in the putative presynaptic cell and monitoring postsynaptic responses in voltage-clamped postsynaptic neurons. Evoked conncctions werc considered monosynaptic if the synaptic delay was less than $5 \mathrm{msec}$ from the peak of the presynaptic action potential to the onset of the postsynaptic response and the synaptic latency remained unchanged with repetitive stimulation. This was confirmed in some experiments by elevating external divalent cations by $2 \mathrm{~mm}$ to reduce neuronal excitability. All drugs were administered via bath application.

Pharmacology test protocols consisted of 20 action potentials stimulated at $2 \mathrm{sec}$ intervals. To reduce variability in synaptic responses, the first response was discarded, and the remaining 19 episodes were averaged.

Data was acquired from two Axopatch 1-C amplifiers using pCLAMP software (v. 5.51, Axon Instruments) and Labmaster hardware (TL-1, Scientific Solutions) after filtering at $1 \mathrm{kHz}$. Records were also digitized and stored on VCR tape (Vetter PCM/VCR).

CNQX (6-cyano-7-nitroquinoxaline-2,3-dione) was purchased from Tocris Neuramin; $\omega$-CgTx GVIA, picrotoxin, and TTX (tetrodotoxin) were from Sigma.

Immunocytochemistry. Presence of synapse-specific proteins was determined by indirect immunocy tochemistry procedures. Primary monoclonal antibodies directed against synaptotagmin (CL 41.1) and rab3a (CL 42.2) were generously provided by R. Jahn, and a polyclonal antibody (CG-454/455) directed against synapsin I was generously supplied by A. Czernik. The antibodies were used at the following dilutions: synaptotagmin (1:250), rab3a (1:50 and 1:500), and synapsin I (1:250). Cells were fixed with $4 \%$ paraformaldehyde in PBS at room temperature for $30 \mathrm{~min}$. After permeabilization with Triton X-100 and incubation with BSA $(5 \%)$ and goat serum $(5 \%)$ to prevent nonspecific binding, primary antibodies were added and the cells were incubated overnight at $4^{\circ} \mathrm{C}$. After washout of the primary antibodies, goat anti-mouse and goat anti-rabbit rhodamine conjugated antibodies (1:200; Fisher) were added and the preparation was incubated for $1 \mathrm{hr}$ at room temperature. In some preparations, after immunochemical staining, the cells were washed with PBS containing $0.1 \% \mathrm{NaBH}_{4}$ for $30 \mathrm{~min}$ at room temperature to reduce autofluorescence (Beisker et al., 1987).

Visualization was accomplished using two separate imaging systems. For most experiments, conventional epifluorescence microscopy was utilized using a silicon intensified target (SIT) camera driven by IMAGE-1/ AT software (v. 4.0, Universal Imaging Corp.).
In some cases, to gain enhanced spatial resolution, a Noran Odyssey real-time laser scanning confocal microscope equipped with IMAGE-1/ AT software (v. 4.0) was used. Optical sections were collected through a $60 \times$ plan-apochromatic objective that gave a single section optical thickness of $0.7 \mu \mathrm{m}$ (full width at half-maximum, FWHM). The initial and final optical planes were specified to ensure that all immunoreactive areas were captured.

Calcium imaging. Calcium levels were estimated using fura-2/AM and ratiometric imaging techniques (Grynkiewicz et al., 1985). All measurements were made from somatic regions. Cells were loaded with fura-2/AM $(2 \mu \mathrm{M})$ for $40 \mathrm{~min}$ at $37^{\circ} \mathrm{C}$. One microliter of $25 \%(\mathrm{w} / \mathrm{w})$ of Pluronic F-127 was mixed per $1 \mathrm{ml}$ of fura-2/AM loading solution (2 $\mu \mathrm{M})$ to aid solubilization of the ester into aqueous medium. After washing, fura-2/AM was deesterified for $40 \mathrm{~min}$ at $37^{\circ} \mathrm{C}$. All experiments took place at $22-24^{\circ} \mathrm{C}$. Normal external saline was (in $\mathrm{mM}$ ) NaCl, 140; $\mathrm{KCl}, 5 ; \mathrm{MgCl}_{2}, 2 ; \mathrm{CaCl}_{2}, 2$; and HEPES, 10 (pH 7.35). In zero-calcium saline, $\mathrm{Ca}^{2+}$ was replaced with $\mathrm{Mg}^{2+}$ and $2 \mathrm{mM}$ EGTA was added.

To test for the presence of voltage-sensitive calcium influx, neurons were incubated in TTX $(1 \mu \mathrm{M})$ to prevent spontaneous action potentials, and were depolarized using elevated potassium saline that was applied by a $30 \mathrm{sec}$ pressure ejection pulse from a puffer pipette $(\sim 2-3 \mu \mathrm{m}$ opening; 5-8 psi). In this saline, $\mathrm{KCl}(50 \mathrm{~mm})$ replaced $\mathrm{NaCl}$.

Image processing and analysis was performed using either QFM ratiometric softwarc and a QX-7 proccssor (Quantex Corp.) or IMAGE-1/ FLUOR (v. $1.63 \mathrm{~g}$, Universal Imaging Corp.). Background subtracted ratio images $(340 / 380 \mathrm{~nm}$ or $350 / 380 \mathrm{~nm})$ were used to calculate the $\left[\mathrm{Ca}^{2+}\right]$ according to Equation 5 of Grynkiewicz et al. (1985).

Calibration of fura-2 was performed in situ (Thomas and Delaville, 1991). Briefly, cells were permeabilized with the calcium ionophore 4-bromo-A23187 (10 $\mu \mathrm{M}$; Molecular Probes) in the presence of $4 \mathrm{~mm}$ calcium to obtain $R_{\max }$, or $0 \mathrm{Ca}^{2+} / 10 \mathrm{mM}$ EGTA to obtain $R_{\min }$. Fura-2 fluorescence was then quenched with $\mathrm{Mn}^{2+}(20 \mathrm{~mm})$ to acquire background fluorescence levels for $R_{\min }$ and $R_{\max }$. In some cases, at the end of an experiment, digitonin $(40 \mu \mathrm{M})$ was added to measure the extent of compartmentalization of Fura-2. In all cases where this was done, compartmentalization was not significant. $R_{\min }$ was $0.17-0.21, R_{\max }$ was 2.86-3.90, and $F_{0} / F_{s}$ was 3.44-10.57. Similar calibration values were obtained when parallel calibrations were performed using fura- 2 pentapotassium salt in vitro. There were no differences in the calibration values between cells at different times in culture. A $K_{d}$ of $224 \mathrm{~nm}$ as previously reported (Grynkiewicz et al., 1985) was used. For experiments where osmolarity was increased by the addition of $300 \mathrm{~mm}$ sucrose, a linear relationship between ionic strength and $K_{d}$ was assumed. The $K_{d}$ was adjusted to $990 \mathrm{nM}$, based on previously reported values (Grynkiewicz et al., 1985).

Cells were kept for further analysis if the calcium accumulation due to the first application of high- $\left[\mathrm{K}^{+}\right]$saline exceeded $50 \%$ of the resting calcium level. Using this criteria $97 \%$ (583 of 600 tested) of neurons were responsive.

For experiments involving application of calcium channel antagonists, DMSO, or zero-calcium, high- $\left[\mathrm{K}^{+}\right]$applications were $12 \mathrm{~min}$ apart. DMSO $(0.1 \%)$, nifedipine $(5 \mu \mathrm{M})$, or zero-calcium saline was uniformly bath applied 5 min prior to the second application of high $\left[\mathrm{K}^{+}\right]$while $\omega$-CgTx $(100 \mathrm{nM})$ and cadmium $(100 \mu \mathrm{M})$ were bath applied at 10 and $1-2$ min prior to the second high- $\left[K^{+}\right]$application.

Only cultures that remained viable for at least 2 weeks, and in which evoked connections were detected in at least $50 \%$ of all pairs assayed electrophysiologically on day 12 , were included in electrophysiology, calcium imaging, and immunocytochemistry analysis.

\section{Results}

\section{Pharmacology of synaptic currents}

As an initial step in characterizing synapse formation between cultured hippocampal neurons, the pharmacological properties of action potential-evoked and spontaneous synaptic currents were examined in neurons cultured from 1 to $14 \mathrm{~d}$. In normal saline spontaneous inhibitory and excitatory synaptic currents were present. While some of these spontaneous synaptic events likely arise from the generation of action potentials in synaptically connected neurons, the majority of the events are due to spontaneous release of neurotransmitter since they were still detected in the presence of TTX $(1 \mu \mathrm{M})$. Bath application of 100 
(A)

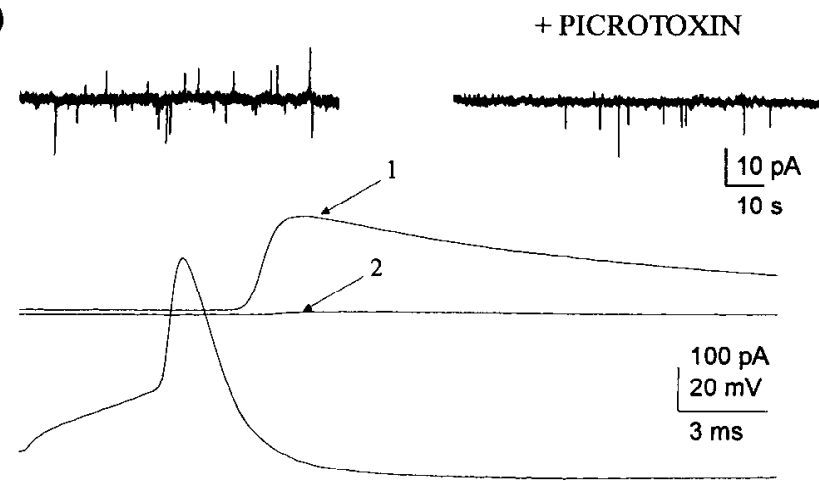

(B)
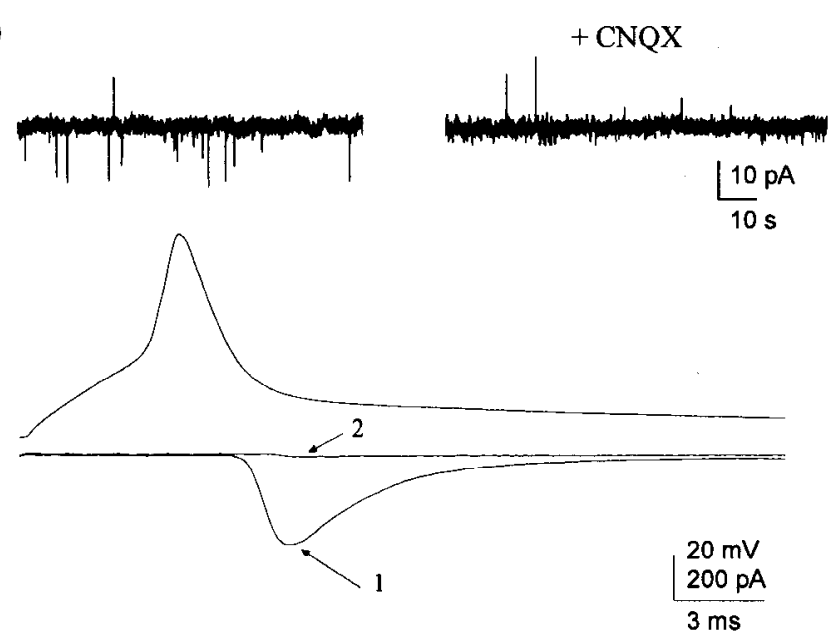

Figure 1. Evoked and spontaneous synaptic connections in hippocampal neurons 12-13 d after plating into culture. A:Upper trace, left, Recording of spontaneous inhibitory and excitatory synaptic events. Right, Inhibitory spontaneous synaptic events are blocked by bath application of $100 \mu \mathrm{m}$ picrotoxin. Lower trace, Evoked inhibitory synaptic connections in normal saline $(I)$ or with bath application of $100 \mu \mathrm{M}$ picrotoxin (2). B:Upper trace, left, Spontaneous inhibitory and excitatory spontaneous synaptic events in a different cell than $A$. Right, Excitatory spontaneous synaptic events are blocked by bath application of $10 \mu_{\mathrm{M}} \mathrm{CNQX}$. Lower trace, Evoked excitatory connections in normal saline (1) are abolished in the presence of CNQX (2). Evoked responses shown are the average of 19 responses evoked at 2 sec intervals. Current and voltage traces are graphically offset for clarity.

$\mu \mathrm{M}$ picrotoxin completely and selectively abolished spontaneous and action potential-evoked synaptic inhibitory currents (Fig. $1 A$ ), while bath application of $10 \mu \mathrm{M} C N Q X$ completely inhibited both action potential-evoked and spontaneous excitatory synaptic currents (Fig. $1 B$ ). This pharmacological profile is consistent with $\mathrm{GABA}_{A}$-mediated inhibitory synaptic responses and CNQX-sensitive non-NMDA-mediated excitatory synaptic events. The absence of an NMDA component may be attributed to the lack of glycine and the presence of $2 \mathrm{mM} \mathrm{MgCl}_{2}$ in the bath saline.

\section{Pharmacology of presynaptic calcium channels}

Since action potentials must admit calcium to trigger transmitter release (Katz, 1969; Mulkey and Zucker, 1991), we examined which calcium channel subtypes mediate calcium influx necessary for neurotransmitter release in 12-13-d-old hippocampal neurons. The specific $\mathrm{N}$-type calcium channel antagonist $\omega$-CgTx was used to determine the contribution of calcium influx through $\mathrm{N}$-type channels in mediating transmitter release. Bath application of $100 \mathrm{nM} \omega-\mathrm{CgTx}$ differentially reduced excitatory and inhibitory synaptic currents. In the presence of $\omega-\mathrm{CgTx}$, excitatory synaptic currents were inhibited $58 \perp 7 \%$ (mean \pm SEM, $n=6$ ), while inhibitory synaptic currents were reduced by 87 $\pm 3 \%(n=15)$ of their initial amplitude (Fig. $2 B, C)$. Thus, $\mathrm{N}$-type calcium channels are required for inhibitory synaptic transmission and contribute calcium for excitatory synaptic transmission. In contrast, the L-type calcium channel antagonist nifedipine ( $5 \mu \mathrm{M})$ did not inhibit either excitatory $(-36 \pm 21 \%$; $n=6)$ or inhibitory $(-9 \pm 6 \% ; n=14)$ synaptic connections (Fig. 2A). The incomplete inhibition of excitatory synaptic transmission supports other observations that multiple subtypes of calcium channels supply calcium to stimulate transmitter release (Takahashi and Momiyama, 1993).

\section{Time course of synapse development}

Having characterized the properties of inhibitory and excitatory synaptic transmission in culture, we examined the temporal pattern of synapse development. Initially, the development of functional hippocampal synapses was examined using electrophysiological approaches. Cultures were assayed for synaptic events at $2 \mathrm{~d}$ intervals ranging from day 2 through day 14 after plating into culture (Fig. 3). Spontaneous synaptic events were detected as early as day 2 in culture. By day 4, spontaneous synaptic events were detected in $32 \pm 13 \%$ of all cells assayed, while evoked connections were only detected in $11 \pm 4 \%$ of all synaptic pairs assayed. On day 12 , spontaneous events were detected in $86 \pm 17 \%$ of all cells assayed, and evoked connections were detected in $75 \pm 22 \%$ of all cell pairs assayed. The temporal pattern of development shows that the appearance of evoked synaptic transmission was delayed in comparison to spontaneous synaptic events (Fig. 3).

Based on this developmental profile we used day 4 and day 12 cultures to represent immature and mature synaptic states. We chose day 4 as it was a time when spontaneous synaptic events were substantially present but evoked connections were still sparse. In contrast, day 12 cultures represented a more synaptically mature state, as determined by the increased number of cells with spontaneous and evoked connections.

\section{Availability of releasable neurotransmitter}

Considering the paucity of spontaneous synaptic events at day 4 in culture, we determined if synaptic events could be induced in cells that were initially synaptically silent ("silent cells") by the application of high-osmolarity saline. Application of highosmolarity saline has been shown to cause an increase in spontaneous transmitter release (Fatt and Katz, 1952; Hubbard et al., 1968; Malgaroli and Tsien, 1992; Manabe et al., 1992). Imaging of intracellular calcium levels during the application of high-osmolarity saline did not reveal a significant difference in the emission ratio of Fura-2 due to excitation at 350 and 380 nm $\left(n=23 ; p>0.7\right.$, Student's $t$ test). However, if the $K_{d}$ of fura- 2 is adjusted for the change in ionic strength that occurs due to the shrinkage of the presynaptic terminal in the presence of high-osmolarity saline (Delaney et al., 1991) a calcium accumulation of $292 \pm 27 \mathrm{nM}$ was observed.

In 12-d-old cultures, application of high-osmolarity saline in the presence of TTX reliably produced a large increase in spontaneous synaptic events (Fig. 4A). Both inhibitory and excitatory 


\section{(A) $5 \mu \mathrm{M}$ NIFEDIPINE}
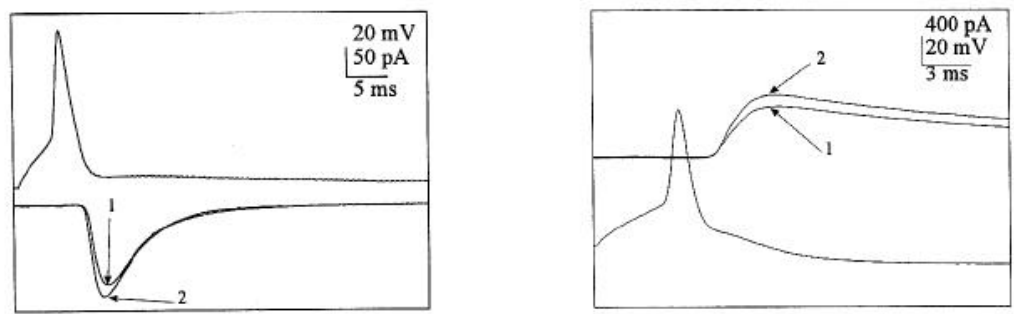

\section{(B) $100 \mathrm{nM}$ CONOTOXIN}
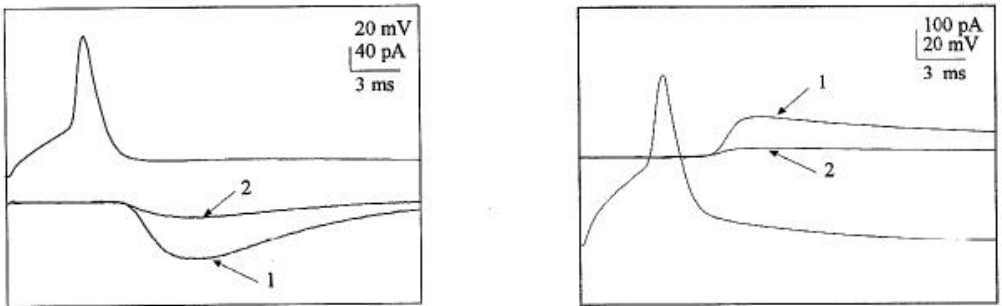

(C)

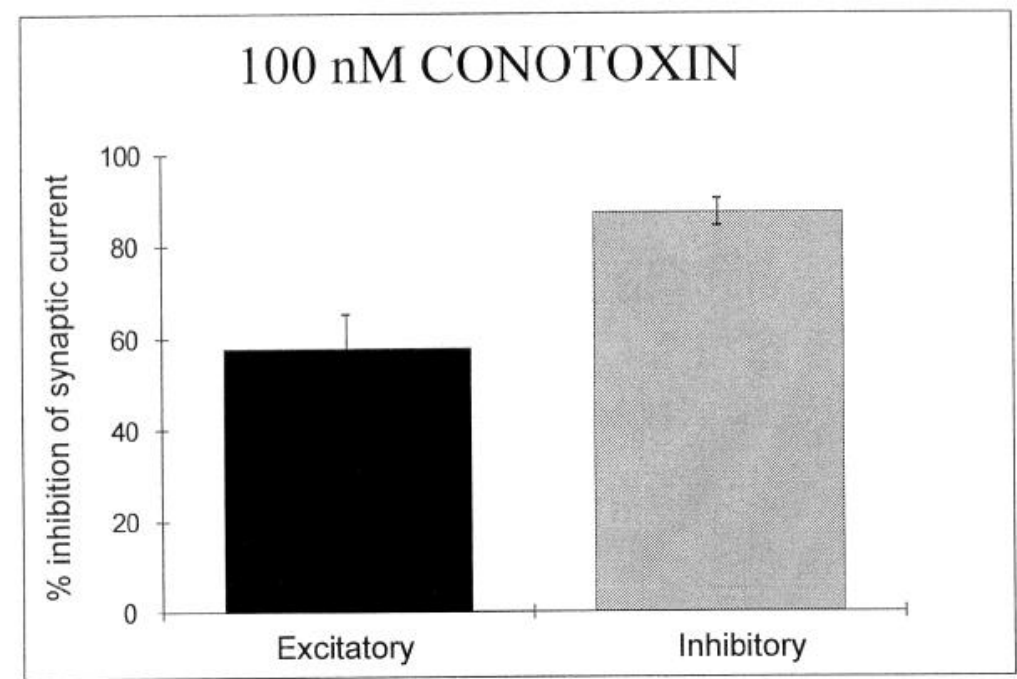

Figure 2. Evoked synaptic responses in 12 DIC hippocampal neurons are not reduced by the L-type calcium channel antagonist nifedipine, but are differentially sensitive to the $\mathrm{N}$-type calcium channel antagonist $\omega$-CgTx. The averaged response at $10 \mathrm{~min}$ post antagonist addition was compared against the initial averaged response. $A$ and $B$, Postsynaptic excitatory (left) and inhibitory (right) responses in the absence $(1)$ or presence (2) of $5 \mu \mathrm{M}$ nifedipine $(A)$ or $100 \mathrm{~nm} \omega-\operatorname{CgTx}(B)$. Current and voltage traces are graphically offset for clarity. Cumulative effect of $\omega-\mathrm{CgTx}$ data from 6 excitatory and 15 inhibitory synaptic pairs is shown in $C$. spontaneous events were induced at 12 DIC. In 4-d-old cultures, spontaneous synaptic events were absent in 27 out of 38 cells examined. Application of high-osmolarity saline to these 27 cells without spontaneous synaptic events resulted in the detection of spontaneous transmitter release in seven of these cells (Fig. $4 B)$ with inhibitory $(n=3)$ and excitatory $(n=4)$ events induced. Thus, even in $26 \%$ of preparations in which no synaptic events were initially detected, postsynaptic receptors and presynaptic release apparatus were present.

\section{Development of synapse-specific proteins}

In the functional synapse, the release of neurotransmitter is dependent on the coupling of calcium channels with a calcium responsive secretory apparatus. As a first step in understanding the rate limiting steps in the development of functional synapses we performed immunocytochemistry to ask whether synaptic proteins are expressed in a temporal pattern similar to that of functional synapse formation. A multitude of synapse-specific proteins implicated in neurotransmitter release have been characterized (for review, see Sudhof and Jahn, 1991; Jessell and Kandel, 1993). We determined if the pattern of expression of the synaptic vesicle protein synaptotagmin (p65), and the vesicle associated proteins synapsin I, and rab3a were developmentally regulated. In immature cultures, synaptotagmin immunoreactivity was localized primarily to the soma with some staining throughout neuritic processes (Fig. $5 A$ ). In contrast, in mature cultures the staining profile was strikingly different, with the appearance of intense punctate staining along neuritic processes (Fig. 5C). This punctate staining is characteristic of synaptic release sites in hippocampal neurons (Bekkers and Stevens, 1989; Fletcher et al., 1991). The appearance of distinct puncta with maturation was also evident for synapsin I, and rab3a (Fig. 6).

To further investigate the cellular localization of these syn- 


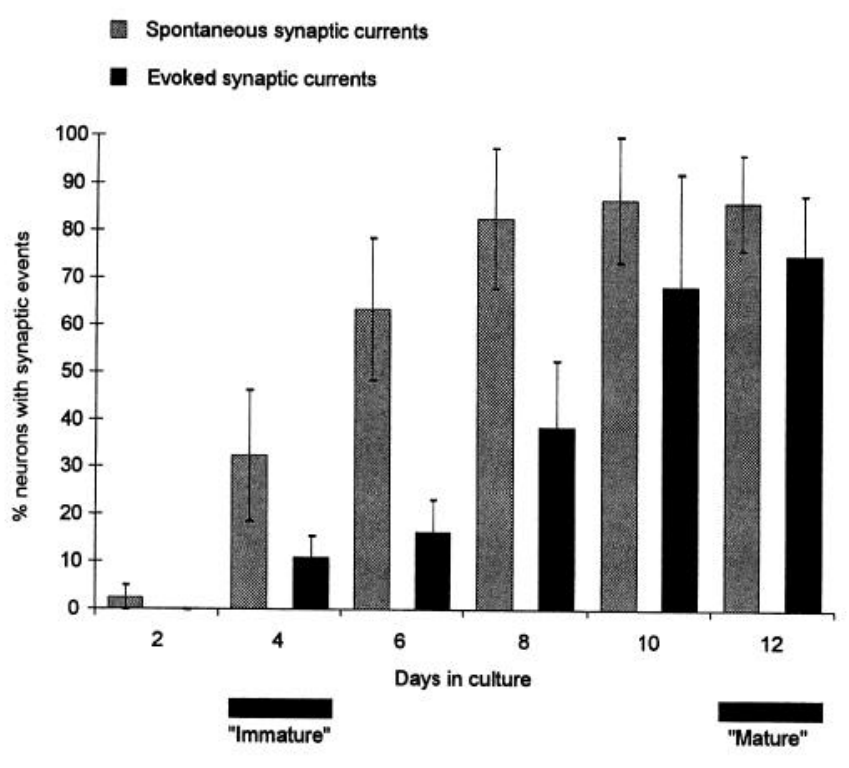

aptic proteins, confocal microscopy was utilized. Optical sectioning revealed the presence of synaptotagmin immunoreactivity in the soma in a pattern consistent with its presence in the Golgi apparatus and throughout the neurites in immature cultures $(73 \%, n=74)$ (Fig. $5 B$ ). In contrast, in mature cultures synaptotagmin immunoreactivity was observed only on the surface of the somatic region, consistent with neuritic-somatic contact sites $(100 \%, n=79)$ (Fig. $5 D)$. Synaptotagmin immunoreactivity in Golgi was not detected in these mature cultures.

Figure 3. Developmental profile of spontaneous and evoked synaptic connections. Hippocampal cultures were assayed for the presence of spontaneous and evoked synaptic currents at various times after plating. The percentage of cells where spontaneous or evoked connections could be detected are shown as a function of days in culture. The horizontal bars arbitrarily represent the developmentally immature state at 4 DIC and the more synaptically mature state at 12 DIC. Each bar represents the mean \pm SEM from a minimum of 33 cells or 30 synaptic pairs at each time point for spontaneous or evoked synaptic events, respectively.

\section{(A) 12 day \\ High Osmo

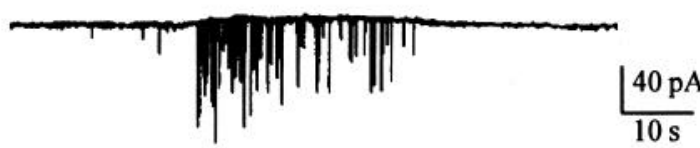

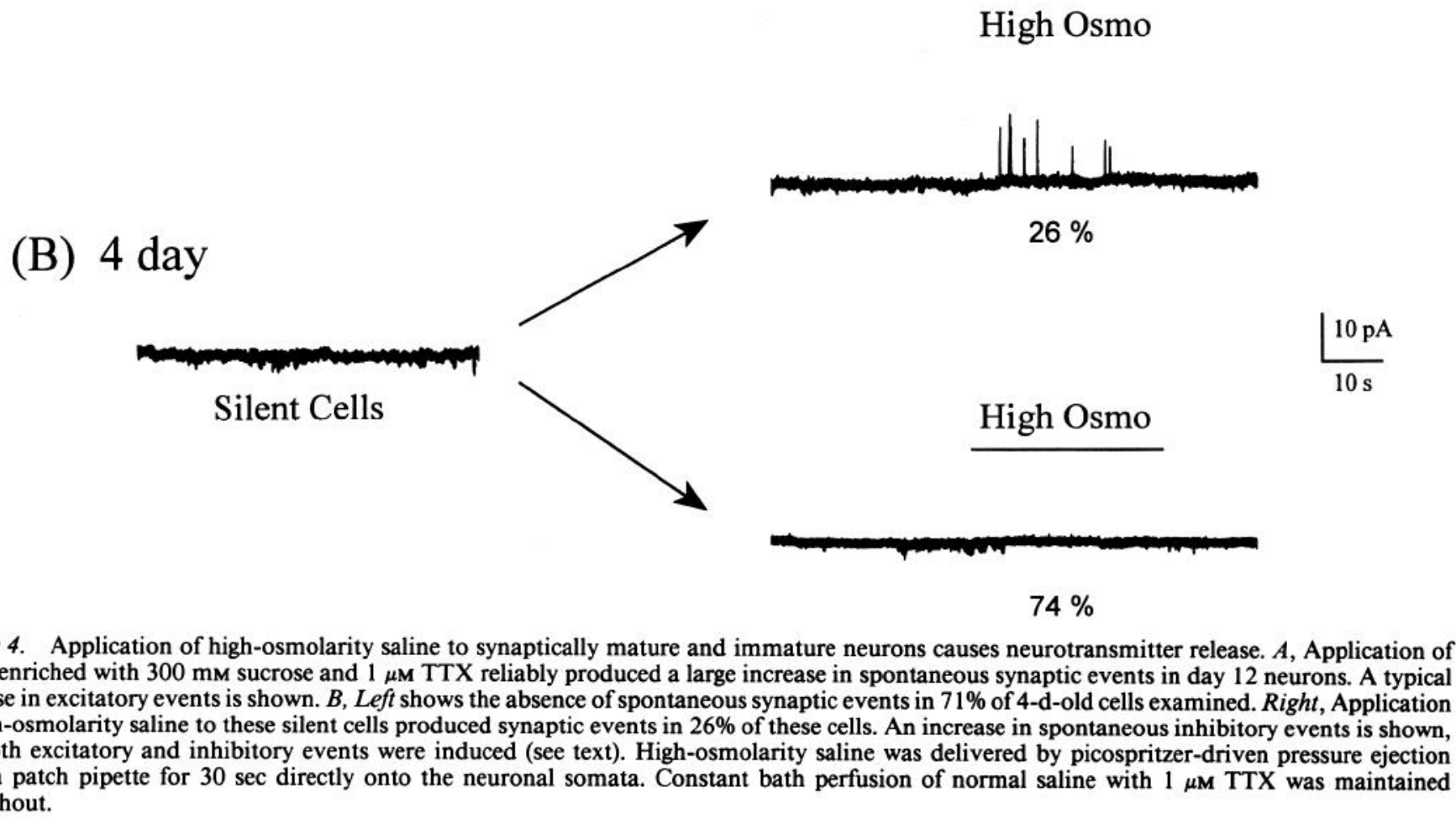


4 Day

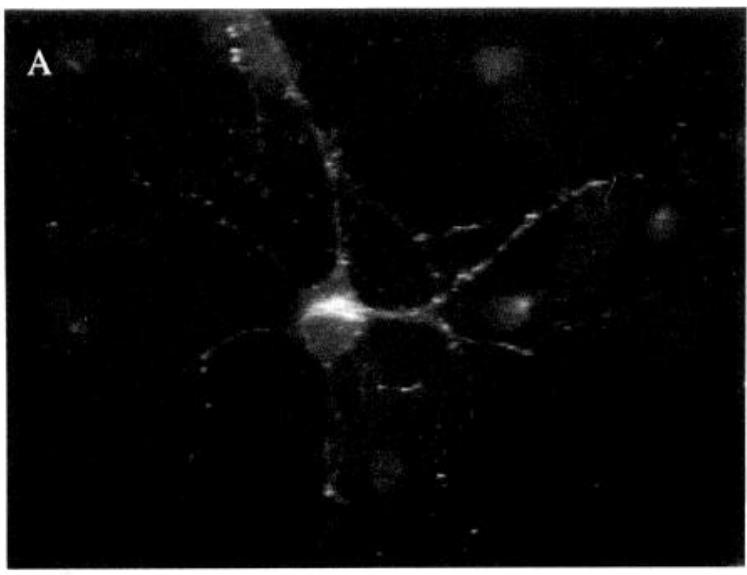

Top View Reconstruction

12 Day

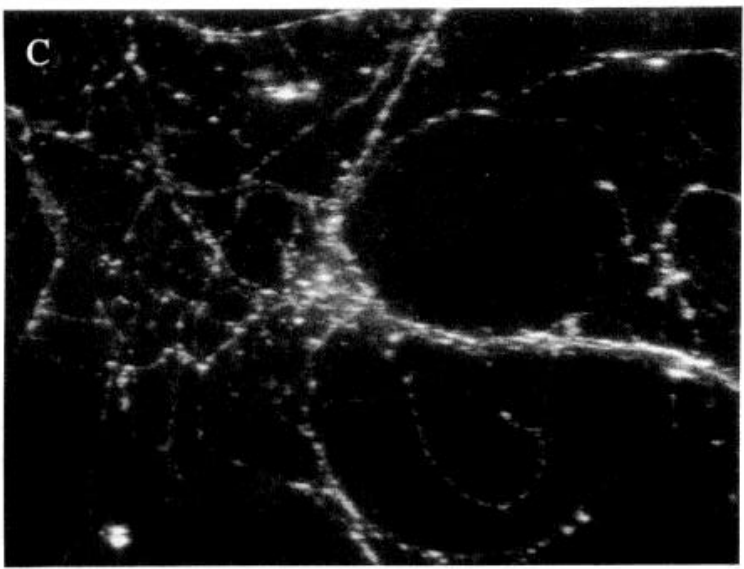

Top View Reconstruction

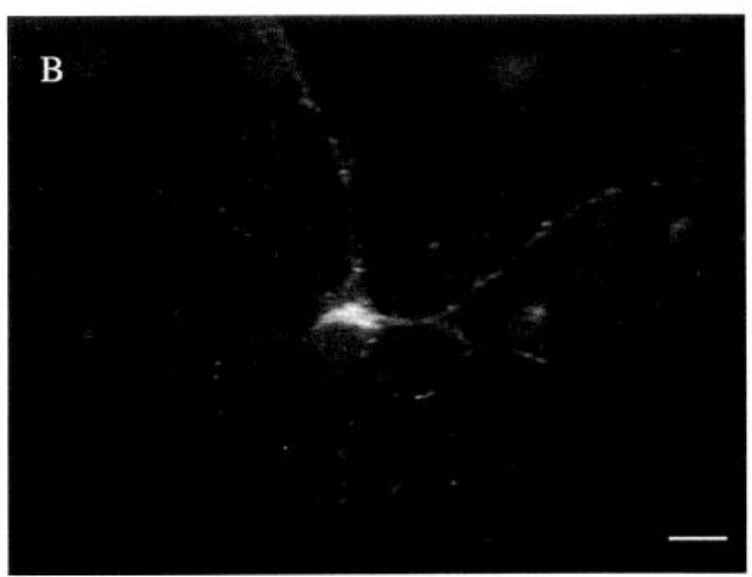

Single Optical Section

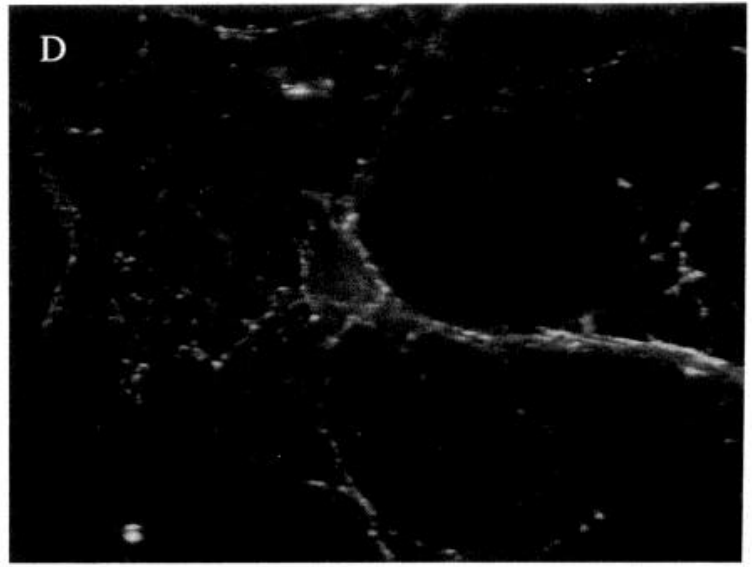

Single Optical Section

Figure 5. Confocal microscopy of synaptotagmin immunoreactivity. $A$, Top view of a composite image reconstructed from 40 optical sections taken at $0.25 \mu \mathrm{m}$ vertical increments from a 4-d-old culture. Intense Golgi and diffuse neuritic staining is apparent. $B$, A single optical section from the middle of the stack of sections used to construct the top view shown in $A$ demonstrating that somatic staining is intracellular. $C$, Top view of a composite image reconstructed from 40 optical sections taken at $0.35 \mu \mathrm{m}$ vertical increments from a 12-d-old culture. Distinct punctate staining is present on neurites and the soma. $D$, Single optical section from the middle of the stack of sections used to construct the top view in $C$ reveals that the somatic staining is not intracellular and is likely due to neurite contact on the soma surface. Scale bar, $10 \mu \mathrm{m}$.

Neuritic staining was exclusively localized to neuritic contact sites. A similar pattern of staining was seen for rab3a and synapsin I. However, in immature cultures these proteins did not show Golgi accumulation, but instead a diffuse pattern throughout the soma and neurites was seen (Fig. 6).

These patterns of immunoreactivity are consistent with previous studies (Fletcher et al., 1991; Matteoli et al., 1991), and in addition we have shown that the immature immunoreactivity profile is temporally correlated with a functionally immature synaptic state of the neurons.

\section{Development of voltage-dependent calcium influx}

Since the $\omega$-CgTx, but not the nifedipine-sensitive calcium channel is involved in evoked synaptic transmission, we have determined the temporal pattern of expression of these two channel types in relation to the formation of functional synaptic connections. As an initial step, the development of high-[K+]evoked calcium influx was examined using conventional calcium imaging techniques. Fifty millimolar $\mathrm{K}^{+}$saline was applied to neurons from a puffer pipette while monitoring the calcium levels of neuronal somata. At all times in culture, high $\left[\mathrm{K}^{+}\right]$ caused an enhancement of neuronal calcium levels that required the presence of calcium in the bathing saline. After greater than $6 \mathrm{~d}$ in culture high $\left[\mathrm{K}^{+}\right]$caused a greater change in the calcium level of neurons. For example, at $4 \mathrm{~d}$ in culture voltage-dependent calcium accumulation due to application of high $\left[\mathrm{K}^{+}\right]$was $224 \pm 10 \mathrm{~nm}$ while by $12 \mathrm{~d}$ in culture it was $466 \pm 28 \mathrm{~nm}$ (Fig. 7).

To further examine the relation between the development of calcium influx and synaptogenesis we studied the contribution of N-type and L-type calcium channels to calcium influx. Using synaptically immature (4 DIC) and mature cultures (12 DIC) we determined the contribution of each channel type to voltagedependent calcium accumulation (Fig. 8). Neurons were depolarized with two applications of elevated $\left[\mathrm{K}^{+}\right]$separated in time by $10 \mathrm{~min}$. Repeated applications of $\left[\mathrm{K}^{+}\right]$reliably elevated calcium levels that are due to calcium influx since omission of calcium from the bathing medium reduced calcium accumu- 
4 Day

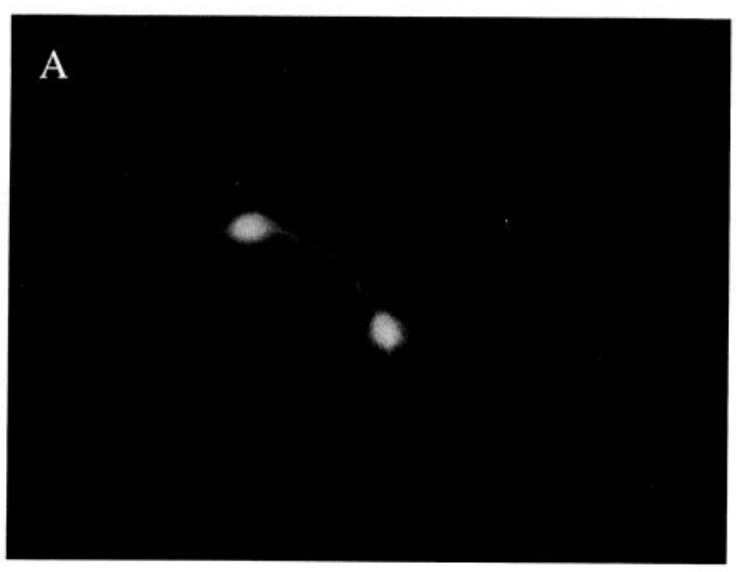

rab3a

\section{Day}

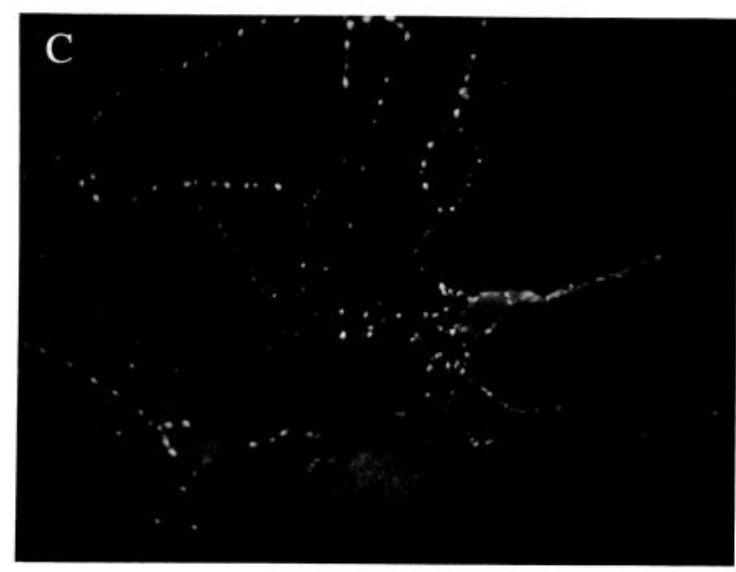

rab3a

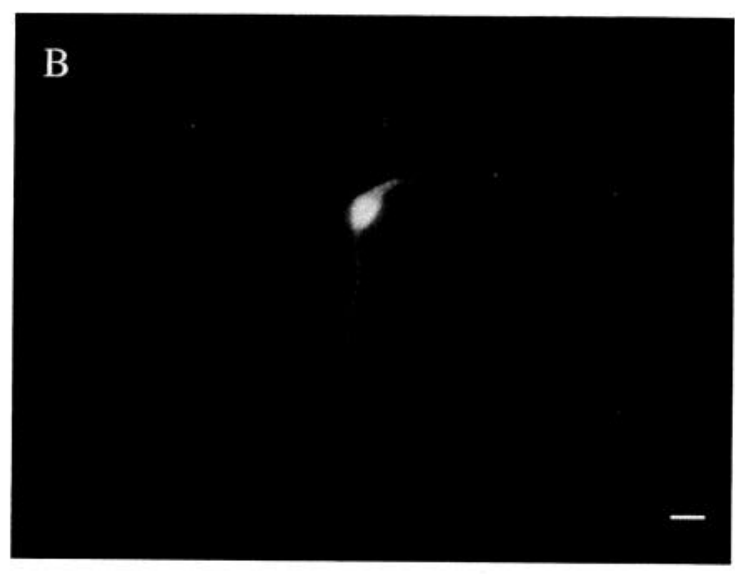

Synapsin I

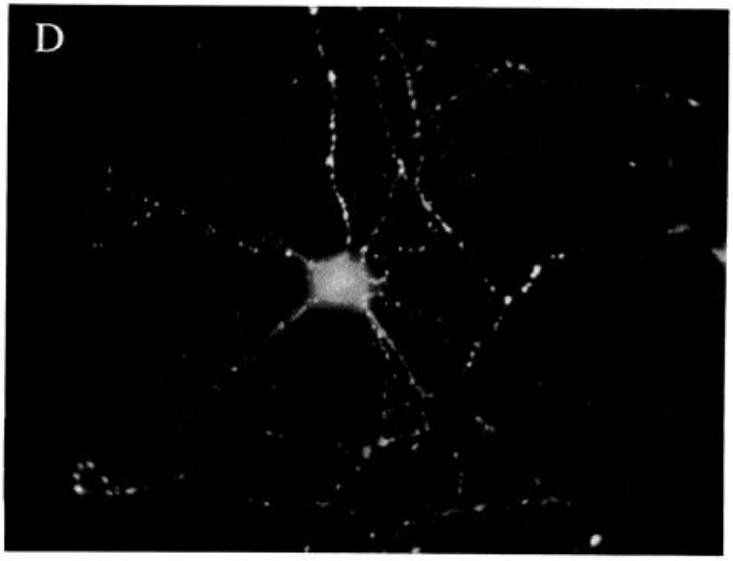

Synapsin I

Figure 6. Conventional epifluorescent immunoreactivity profiles of rab3a and synapsin I. $A$ and $B$, Distribution of rab3a $(A)$ and synapsin I ( $B)$ from a 4-d-old culture. Somatic and neuritic staining is evident. Punctate varicose staining of rab3a $(C)$ and synapsin $I(D)$ is apparent in $12-\mathrm{d}$ old cultures. Scale bar, $10 \mu \mathrm{m}$.

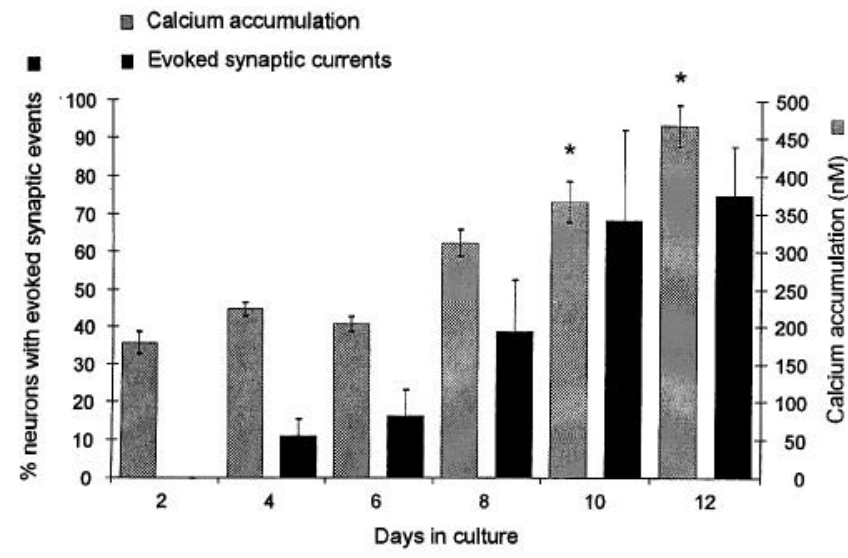

Figure 7. Potassium-evoked calcium accumulation increases in a pattern parallel to that of synapse formation. A statistically significant increase in calcium accumulation was first observed at $10 \mathrm{DIC}$ as compared to 4 DIC. Points represent mean \pm SEM. Calcium accumulation was determined from a minimum of 39 cells at each time period. Statistical significance $(*)$ was established at $p<0.01$ using one-way ANOVA with post hoc Scheffe's test. lation $(98 \pm 1 \%, n=30)$ or cadmium $(100 \mu \mathrm{M})$, a general calcium channel antagonist, reduced calcium accumulation by $72 \pm 3 \%$ $(n=27, p<0.01)$.

In synaptically immature neurons, $76 \pm 2 \%(n=36)$ of the calcium influx is mediated by L-type nifedipine-sensitive channels (Fig. 8). The nifedipine carrier DMSO $(0.1 \%)$ did not attenuate calcium influx $(n=33)$. In contrast to nifedipine, addition of $\omega-\mathrm{CgTx}$ at this same stage in culture did not affect the voltage-dependent calcium accumulation $(4 \pm 3 \%$ inhibition, $n$ $=29$ ) indicating that L- but not $\mathrm{N}$-type calcium channels are expressed in neuronal somata in synaptically immature neurons. In synaptically mature neurons when the calcium accumulation has increased from 224 to $466 \mathrm{nM}$, nifedipine still attenuated the calcium accumulation causing a $67 \pm 2 \%(n=34)$ reduction in high- $\left[\mathrm{K}^{+}\right]$-evoked calcium accumulation. Additionally, at this time, an $\omega-\mathrm{CgTx}$-sensitive component to calcium influx has developed. Addition of $100 \mathrm{~nm} \omega-\mathrm{CgTx}$ attenuated the $\left[\mathrm{K}^{+}\right]-$ evoked calcium accumulation by $43 \pm 4 \%(n=39)$. This indicates that both $\mathrm{L}$ - and $\mathrm{N}$-type calcium channels are being functionally expressed in the somata of synaptically mature neurons. Since evoked synaptic connections are sensitive to the 
(A) 4 Day
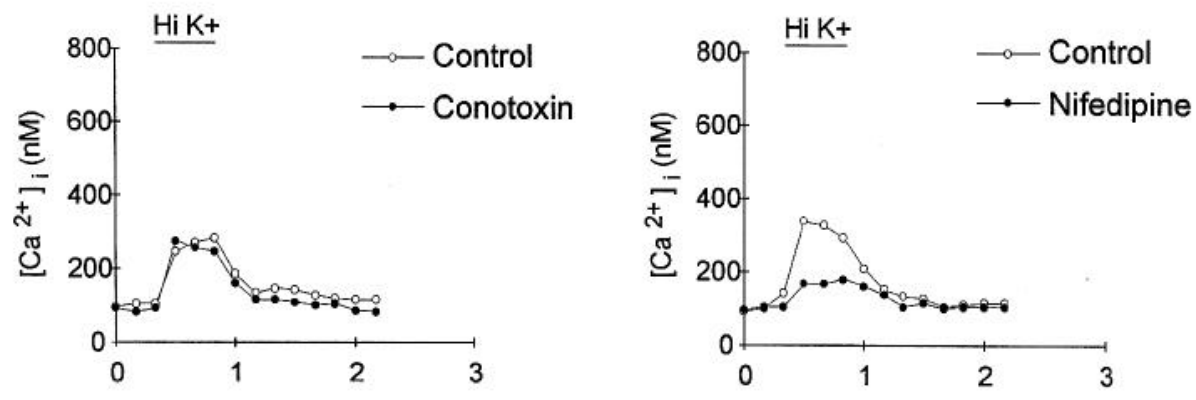

(B) 12 Day
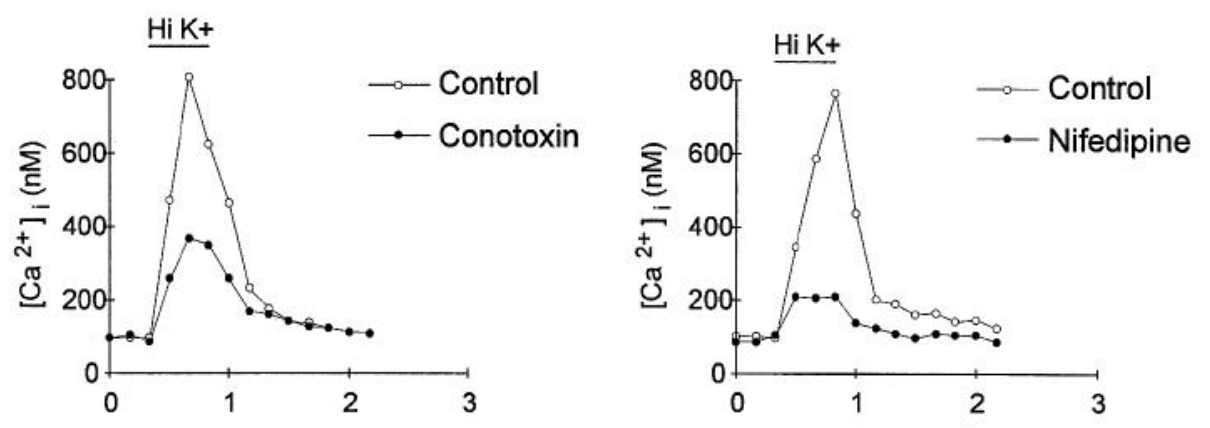

(C)

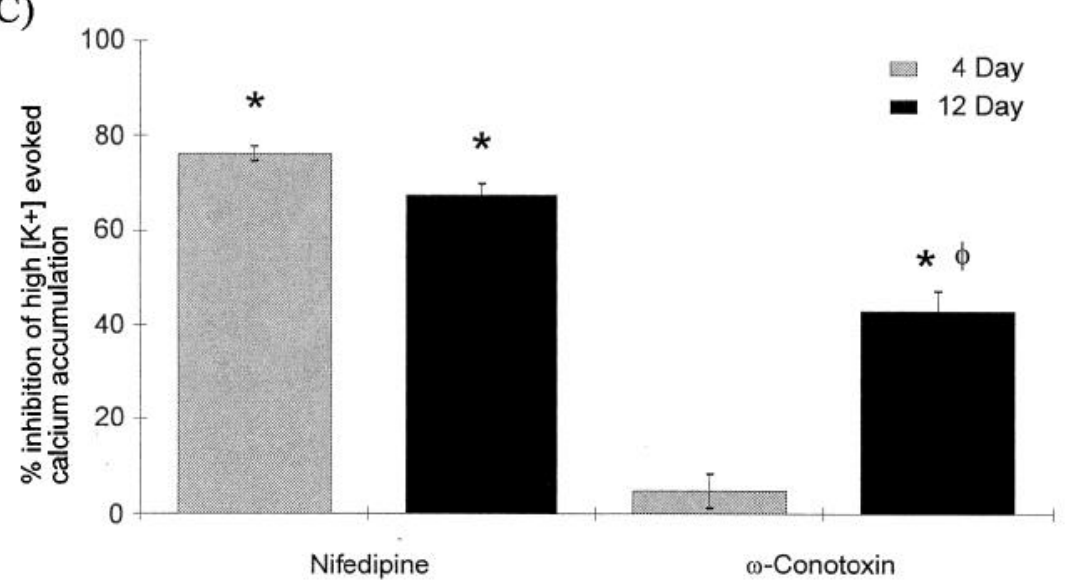

Figure 8. Calcium channel subtypes mediating calcium influx; $100 \mathrm{~nm}$ $\omega$-CgTx or $5 \mu \mathrm{M}$ nifedipine was bath applied to synaptically immature $4 \mathrm{~d}$ cultures or synaptically mature $12 \mathrm{~d}$ cultures. $A$ and $B$, Calcium levels in response to high- $\left[\mathrm{K}^{+}\right]$application measured from single 4- or 12-d-old cells in the presence or absence of antagonist. $C$, Summary of inhibition of high$\left[\mathrm{K}^{+}\right]$-evoked calcium accumulation. Inhibition was calculated as the percentage inhibition of calcium accumulation during the second application $\left(\Delta \mathrm{Ca}_{2}\right)$ of high $\left[\mathrm{K}^{+}\right]$compared to the first $\left(\Delta \mathrm{Ca}_{1}\right)$ : inhibition $=100 \times(1-$ $\left.\left[\Delta \mathrm{Ca}_{2} / \Delta \mathrm{Ca}_{1}\right]\right)$, where $\Delta \mathrm{Ca}=$ peak $\left[\mathrm{Ca}^{2+}\right]_{i}$ subtracted from resting $\left[\mathrm{Ca}^{2+}\right]_{i}$. Each culture dish was exposed to only one treatment. The significance of the effects on high- $\left[\mathrm{K}^{+}\right]$-evoked calcium accumulation was established at $p<0.01$ (*) using one-way ANOVA with post hoc Scheffe's test. Comparison of nifedipine and $\omega$-CgTx-sensitive components at 4 and 12 DIC revealed a significant $(\phi, p<0.01)$ increase of the $\omega-\mathrm{CgTx}$-sensitive component from 4 DIC to 12 DIC. Bars represent means \pm SEM.

$\mathrm{N}$-type calcium channel antagonist $\omega-\mathrm{CgTx}$, the timing of the development of functional synaptic transmission may reflect the appearance of functional $\mathrm{N}$-type calcium channels.

\section{Discussion}

The formation of chemical synapses in the nervous system is the result of the complex interplay between a series of developmental events. Neuronal growth cones are responsible for guiding the extension of the axon to the target field where local interactions with potential synaptic targets regulate the development of presynaptic apparatus and the formation of the functional synapse. The interactions between future synaptic partners that subsequently lead to synapse formation are ill defined.

Much of our understanding of presynaptic development has arisen from a few model systems. For example, chick ciliary ganglion neurons and dissociated neurons from Xenopus spinal cord can release transmitter before contacting synaptic targets
(Young and Poo, 1983). This suggests that presynaptic neurons contain much of the machinery necessary for synaptic transmission in the absence of signals supplied by target cells. Studies on identified neurons of Helisoma have similarly shown that one presynaptic neuron, B5, is promiscuous and forms novel synapses with all synaptic targets tested (Haydon and Kater, 1988; Haydon and Zoran, 1989). When contact is made between such cells, functional synaptic interactions are detected within seconds of target contact, indicating that presynaptic machinery has been presynthesized in preparation for synapse formation. In contrast, another identified neuron of Helisoma, B19, is selective in synapse formation (Haydon and Kater, 1988; Haydon and Zoran, 1989; Zoran et al., 1989, 1990, 1991). Many hours of contact, and protein synthesis are necessary for the presynaptic neuron B19 to gain the ability to couple presynaptic action potentials with neurotransmitter release. Thus, different neurons may use different strategies during synapse formation. While 
some presynthesize presynaptic apparatus, others require instructive cues from target cells to complete the developmental expression of presynaptic ion channels and synaptic proteins.

In hippocampal neurons there are several days of neuronneuron contact before functional synaptic transmission is detected. At $4 \mathrm{~d}$ in culture only $11 \%$ of neuron pairs have evoked synaptic transmission while by day 12 it has increased to $75 \%$. Correlated with this change in detectability of functional synapses are several changes in the cellular properties of the presynaptic cell. Synaptically immature preparations do express synaptic proteins rab3a, synapsin I, and synaptotagmin. However, immunocytochemistry indicates that the distribution of these synaptic markers changes from one in which there is significant somatic immunostaining to punctate staining restricted to varicose boutons in mature synaptic cultures. It is likely that this change in distribution of synaptic proteins, and associated vesicles, accounts in part for the slow acquisition of functional synaptic transmission.

Addition of high-osmolarity medium to neurons in 4 DIC cultures stimulates the release of transmitter. Because transmission can be detected in response to high-osmolarity medium at early times in culture, the development of action potentialevoked transmitter release is likely to be limited by the acquisition of presynaptic properties rather than by the presence of postsynaptic receptors. In support of this possibility, Craig et al. (1993) have shown that AMPA-sensitive channels are expressed in hippocampal neurons in the absence of contact by presynaptic axons at early times in culture. The ability to release transmitter, as detected by spontaneous synaptic currents and high-osmolarity medium, indicates that much of the presynaptic apparatus is functional. Even though much of the release apparatus is present, action potentials rarely evoke transmitter release. A number of possibilities may account for these observations. Perhaps a limited pool of vesicles contributes to this low probability of detecting synapses. Additionally, the calciumsecretion coupling mechanism or calcium influx through the appropriate calcium channels may not be fully developed at this stage in culture. An increase in neurite outgrowth could also increase the number of putative contact sites, resulting in an increase in the detectability of evoked secretion. Finally, axonal versus dendritic differentiation may be changing in parallel with synapse formation.

Inhibitory and excitatory synapses are sensitive to $\omega$-CgTx, but not nifedipine. While other calcium channel subtypes may also be required for synaptic transmission, we chose to compare the development of one calcium channel involved directly in transmitter release (N-type) with one channel that does not stimulate release (L-type). An examination of the development of nifedipine-sensitive and $\omega-\mathrm{CgTx}$-sensitive calcium influx demonstrated that L- and $\mathrm{N}$-type calcium channels are functionally expressed at different times in relation to synaptogenesis. L-type channels, which do not stimulate transmitter release, develop prior to the onset of functional transmission, whereas N-type channels that contribute calcium in transmitter release, appear at a later time in development when synaptic transmission has been established.

\section{References}

Basarsky TA, Parpura V, Haydon PG (1992) Development of functional synaptic transmission between cultured rat hippocampal neurons. Soc Neurusci Abstr 18:1113.

Beisker W, Dolbeare F, Gray JW (1987) An improved immunocy- tochemical procedure for high-sensitivity detection of incorporated bromodeoxyuridine. Cytometry 8:235-239.

Bekkers JM, Stevens CF (1989) NMDA and non-NMDA receptors are co-localized at individual excitatory synapses in cultured rat hippocampus. Nature 341:230-233.

Craig AM, Blackstone CD, Banker G (1993) The distribution of glutamate receptors in cultured rat hippocampal neurons: postsynaptic clustering of AMPA-selective subunits. Neuron 10:1055-1068.

Dai Z, Peng HB (1993) Elevation in presynaptic $\mathrm{Ca}^{2+}$ level accompanying initial nerve-muscle contact in tissue culture. Neuron 10: 827-837.

Delaney K, Tank DW, Zucker RS (1991) Presynaptic calcium and serotonin-mediated enhancement of transmitter release at crayfish neuromuscular junction. J Neurosci 11:631-643.

Falls DL, Harris DA, Johnson FA, Morgan MM, Corfas G and Fischbach GD (1990) $M_{r} 42,000$ ARIA: a protein that may regulate the accumulation of acetylcholine receptors at developing chick neuromuscular junctions. Cold Spring Harbor Symp Quant Biol 55:397406.

Fatt P, Katz B (1952) Spontaneous subthreshold activity at motor nerve endings. J Physiol (Lond) 117:109-128.

Fletcher TL, Cameron P, De-Camilli P, Banker G (1991) The distribution of synapsin I and synaptophysin in hippocampal neurons developing in culture. J Neurosci 11:1617-1626.

Funte LR, Haydon PG (1993) Synaptic target contact enhances presynaptic calcium influx by activating cAMP-dependent protein kinase during synaptogenesis. Neuron 10:1069-1078.

Grynkiewicz G, Poenie M, Tsien RY (1985) A new generation of $\mathrm{Ca}^{2+}$ indicators with greatly improved fluorescence properties. J Biol Chem 260:3440-3450.

Hamill OP, Marty A, Neher E, Sakmann B, Sigworth FJ (1981) Improved patch-clamp techniques for high-resolution current recording from cells and cell-free membrane patches. Pfluegers Arch 391:85100.

Haydon PG, Kater SB (1988) The differential regulation of formation of chemical and electrical connections in Helisoma. J Neurobiol 19: 636-655.

Haydon PG, Zoran MJ (1989) Formation and modulation of chemical connections: evoked acetylcholine release from growth cones and neurites of specific identified neurons. Neuron 2:1483-1490.

Hubbard JI, Jones SF, Landau EM (1968) An examination of the effects of osmotic pressure changes upon transmitter release from mammalian motor nerve terminals. J Physiol (Lond) 197:639-657.

Huettner JE, Baughman RW (1986) Primary culture of identified neurons from the visual cortex of postnatal rats. J Neurosci 6:3044-3060.

Jessell TM, Kandel ER (1993) Synaptic transmission: a bidirectional and self-modifiable form of cell-cell communication. Cell 72:1-30.

Katz B (1969) The release of neural transmitter substances. Liverpool: Liverpool UP.

Leifer D, Lipton SA, Barnstable CJ, Masland RH (1984) Monoclonal antibody to Thy-1 enhances regeneration of processes by rat retinal ganglion cells in culture. Science 224:303-306.

Malgaroli A, Tsien RW (1992) Glutamate-induced long-term potentiation of the frequency of miniature synaptic currents in cultured hippocampal neurons. Nature 357:134-139.

Manabe T, Renner P, Nicoll RA (1992) Postsynaptic contribution to long-term potentiation revealed by the analysis of miniature synaptic currents. Nature 355:50-55.

Matteoli M, Takei K, Cameron R, Hurlbut P, Johnston PA, Sudhof TC, Jahn R, De-Camilli P (1991) Association of Rab3A with synaptic vesicles at late stages of the secretory pathway. J Cell Biol 115: 625-633.

Mattson MP, Kater SB (1989) Development and selective neurodegeneration in cell cultures from different hippocampal regions. Brain Res 490:110-125.

McMahan UJ (1990) The agrin hypothesis. Cold Spring Harbor Symp Quant Biol 55:407-418.

Mulkey RM, Zucker RS (1991) Action potentials must admit calcium to evoke transmitter release. Nature 350:153-155 [published erratum appears in Nature 351:419, 1991].

Simon SM, I linas RR (1985) Compartmentalization of the submembrane calcium activity during calcium influx and its significance in transmitter release. Biophys J 48:485-498.

Sudhof TC, Jahn R (1991) Proteins of synaptic vesicles involved in exocytosis and membrane recycling. Neuron 6:665-677. 
Sun YA, Poo MM (1987) Evoked release of acetylcholine from the growing embryonic neuron. Proc Natl Acad Sci USA 84:2540-2544. Takahashi T, Momiyama A (1993) Different types of calcium channels mediate central synaptic transmission. Nature 366:156-158.

Thomas AP, Delaville F (1991) The use of fluorescent indicators for measurements of cytosolic-free calcium concentration in cell populations and single cells. In: Cellular calcium: a practical approach (McCormack JG, Cobbold PH, eds), pp 1-54. London: Oxford UP. Xie ZP, Poo MM (1986) Initial events in the formation of neuromuscular synapse: rapid induction of acetylcholine release from embryonic neuron. Proc Natl Acad Sci USA 83:7069-7073.

Young SH, Poo MM (1983) Spontaneous release of transmitter from growth cones of embryonic neurones. Nature 305:634-637.

Zoran MJ, Haydon PG, Matthews PJ (1989) Aminergic and pepti- dergic modulation of motor function at an identified neuromuscular junction in Helisoma. $\mathrm{J}$ Exp Biol 142:225-243.

Zoran MJ, Doyle RT, Haydon PG (1990) Target-dependent induction of secretory capabilities in an identified motoneuron during synaptogenesis. Dev Biol 138:202-213.

Zoran MJ, Doyle RT, Haydon PG (1991) Target contact regulates the calcium responsiveness of the secretory machinery during synaptogenesis. Neuron 6:145-151.

Zoran MJ, Funte LR, Kater SB, Haydon PG (1993) Neuron-muscle contact changes presynaptic resting calcium set-point. Dev Biol 158: 163-171.

Zucker RS, Fogelson AL (1986) Relationship between transmitter release and presynaptic calcium influx when calcium enters through discrete channels. Proc Natl Acad Sci USA 83:3032-3036. 